\title{
IL-12 induces autophagy in human breast cancer cells through AMPK and the PI3K/Akt pathway
}

\author{
YAN LIN, WENBIN KUANG, BITAO WU, CHANGLI XIE, CUIYIN LIU and ZHIGUANG TU \\ Ministry of Education Key Laboratory of Laboratory Medical Diagnostics, School of Laboratory Medicine, \\ Chongqing Medical University, Chongqing 400016, P.R. China
}

Received September 30, 2016; Accepted March 31, 2017

DOI: $10.3892 / \mathrm{mmr} .2017 .7114$

\begin{abstract}
Interleukin-12 (IL-12) serves an important role in immune responses and antitumor activity. The study of the association between autophagy and cancer cells remains controversial. The present study aimed to investigate the effect of IL-12 on autophagy in the human breast cancer cell lines MDA-MB-231 and MCF-7, and the possible molecular mechanism. Breast cancer cells were treated with different concentrations of recombinant IL-12. The expression of the autophagy-associated protein microtubule-associated protein light chain 3 (LC3) was determined using western blot analysis, fluorescein isothiocyanate-labeled LC3 was detected using fluorescence microscopy and autophagosomes were examined using transmission electron microscopy. Alterations in the phosphatidylinositol 3-kinase/Rac- $\alpha$ serine/threonine protein kinase (PI3K/Akt) and 5'-AMP-activated protein kinase subunit $\beta$-1 (AMPK) pathways, in addition to pathway-associated proteins, were detected using western blotting, following treatment with IL-12 and pretreatment with the PI3K/Akt activator insulin-like growth factor or the AMPK inhibitor compound C. It was observed that IL-12 was able to upregulate the expression of the autophagy-associated protein LC3 in a concentration- and time-dependent manner, and induce the formation of autophagosomes in the two cell lines, and that the above effects involved the inhibition of the PI3K/Akt signaling pathway and the activation of the AMPK signaling pathway.
\end{abstract}

\section{Introduction}

Breast cancer is the leading cause of cancer mortality in women worldwide (1). Approximately one-half of breast cancer cases

Correspondence to: Professor Zhiguang Tu, Ministry of Education Key Laboratory of Laboratory Medical Diagnostics, School of Laboratory Medicine, Chongqing Medical University, 1 Medical School Road, Chongqing 400016, P.R. China

E-mail: tuzhiguang@aliyun.com

Key words: autophagy, breast cancer, interleukin-12, phosphatidylinositol 3-kinase/Rac- $\alpha$ serine/threonine protein kinase, 5'-AMP-activated protein kinase subunit $\beta$-1 and $60 \%$ of cancer mortalities occur in economically developing countries (2). Autophagy is a self-digestion mechanism for degrading damaged organelles and misfolded proteins in lysosomal compartments (3). Under metabolic stress, autophagy maintains a balance between synthesis, degradation and the subsequent recycling of macromolecules and organelles, in order to promote survival. Autophagy has been hypothesized to serve tumor suppressive and tumor promoting functions $(4,5)$. These paradoxical effects may be due to alterations in the role of autophagy in cancer depending on the tumor types and the stage of tumorigenesis (6,7). Previous research into breast cancer has demonstrated that autophagy activation may suppress tumorigenesis. Liang et al (8) reported that the growth of MCF-7 breast cancer cells was suppressed by overexpression of beclin 1, an autophagy marker gene. Qu et al (9) and Yue et al (10) observed that 40-75\% of human breast cancer, ovarian carcinoma and prostate cancer cells were beclin 1-deficient. Kondo and Kondo (11) reported that beclin 1 protein acted as a tumor suppressor by inhibiting cell proliferation and tumorigenesis in vitro and in vivo. It was additionally reported that autophagy-dependent cell death was induced by numerous anti-cancer drugs, including tamoxifen, rapamycin, arsenic trioxide and histone deacetylase inhibitors. Therefore, activating the autophagy pathway may be an effective way to inhibit breast cancer tumorigenesis.

The antitumor effects of interleukin (IL)-12 have been demonstrated in previous studies (12). IL-12 suppresses tumor growth by activating a number of types of immunity-associated cells, including T cells, macrophages and dendritic cells $(13,14)$. IL-12 has been demonstrated to inhibit the growth of tumors by reducing nutrition and oxygen provision, through suppression of the growth of blood vessels (15). Tumor-associated cytokines secreted by cancer cells are activated or inhibited by IL-12. A previous study demonstrated that IL-12 was able to induce monocytic tumor cell polarization to macrophage-like cells through the up-regulation of the expression and phosphorylation of macrophage colony-stimulating factor 1 receptor (16). However, the mechanism underlying the antitumor effects of IL-12 remains to be elucidated. Additionally, the effects on tumor cell autophagy induced by IL-12, and the underlying mechanism, have not been reported.

In the present study, the induction of autophagy by IL-12 was investigated in human breast cancer cells, in addition to the possible signaling pathways involved, with the aim of 
providing novel research into the mechanism of IL-12-mediated antitumor effects.

\section{Materials and methods}

Cell lines and cell culture. The MDA-MB-231 and MCF-7 human breast cancer cells were obtained from the Type Culture Collection of the Chinese Academy of Sciences (Shanghai, China). Cells were cultured in Dulbecco's modified Eagle's medium (Gibco; Thermo Fisher Scientific, Inc., Waltham, MA, USA) supplemented with $10 \%$ fetal bovine serum (FBS; Biological Industries, Beit-Haemek, Israel), $100 \mathrm{U} / \mathrm{ml}$ penicillin and $100 \mu \mathrm{g} / \mathrm{ml}$ streptomycin (both Invitrogen; Thermo Fisher Scientific, Inc.) at $37^{\circ} \mathrm{C}$ in a humidified atmosphere of $5 \% \mathrm{CO}_{2}$. Human breast cancer cells $\left(1 \times 10^{6}\right)$ were cultured in 6-well culture dishes at $37^{\circ} \mathrm{C}$. When the cells had grown to $60 \%$ confluence, they were treated with recombinant (r) IL-12 (PeproTech, Inc., Rocky Hill, NJ, USA) at a concentration of $5 \mathrm{ng} / \mathrm{ml}$ for $1,2,3,6,12$ or $24 \mathrm{~h}$, or for $12 \mathrm{~h}$ at concentrations of $0.1,0.5,1,5,10$ or $20 \mathrm{ng} / \mathrm{ml}$ at $37^{\circ} \mathrm{C}$. In addition, breast cancer cells were pretreated with $100 \mathrm{ng} / \mathrm{ml}$ insulin-like growth factor 1 (IGF-1; R\&D Systems, Inc., Minneapolis, MN, USA) or $10 \mu \mathrm{mol} / \mathrm{ml}$ BML-275 (Enzo Life Sciences, Inc., Farmingdale, NY, USA) for $2 \mathrm{~h}$ at $37^{\circ} \mathrm{C}$ prior to treatment with $5 \mathrm{ng} / \mathrm{ml} \mathrm{rIL-12}$. The positive group was starved using $1 \%$ FBS (Biological Industries) at $37^{\circ} \mathrm{C}$ for $3 \mathrm{~h}$.

Western blot analysis. MDA-MB-231 and MCF-7 cells were harvested, rinsed 3 times with pre-cooled PBS and lysed in $100 \mu 1$ radioimmunoprecipitation assay buffer (Beyotime Institute of Biotechnology, Haimen, China) containing $1 \mu \mathrm{l}$ $\mathrm{NaF}(500 \mathrm{mM}), 1 \mu \mathrm{l} \mathrm{Na}_{3} \mathrm{VO}_{4}(100 \mathrm{mM})$ and $1 \mu \mathrm{l}$ protease inhibitor phenylmethylsulfonyl fluoride $(100 \mathrm{mM})$ for $30 \mathrm{~min}$ on ice, followed by centrifuging for $30 \mathrm{~min}$ at $15,000 \mathrm{x} \mathrm{g}$ and $4^{\circ} \mathrm{C}$. The protein concentrations were determined using a bicinchoninic acid protein assay kit (Beyotime Institute of Biotechnology). Equal amounts of total protein $(50 \mu \mathrm{g} / \mathrm{lane})$ were electrophoresed on a $12 \%$ SDS-PAGE gel, followed by transfer to polyvinylidene fluoride $(0.22 / 0.45 \mu \mathrm{m})$ membranes using a Trans-Blot system (Bio-Rad Laboratories, Inc., Hercules, CA, USA). The membranes were blocked with $5 \%$ non-fat milk for $1 \mathrm{~h}$ at room temperature and incubated overnight at $4^{\circ} \mathrm{C}$ with specific primary antibodies as follows: Rabbit anti-microtubule-associated protein light chain 3 (LC3) I and II (cat no. NB600-1384; 1:1,000; NOVUS Biologicals, LLC, Littleton, CO, USA); rabbit anti- $\beta$-actin (cat no. 9587; 1:2,000; ImmunoWay Biotechnology Co., Plano, TX, USA); rabbit anti-phosphatidylinositol 3-kinase (PI3K)/Rac- $\alpha$ serine/threonine protein kinase (Akt; cat no. 4691) and phosphorylated (p)-PI3K/p-Akt (cat no. 4060; 1:1,000; Cell Signaling Technology, Inc., Danvers, MA, USA); rabbit anti-5'-AMP-activated protein kinase subunit $\beta$-1 (AMPK; cat no. 2795) and p-AMPK (cat no. 2535; 1:1,000; Cell Signaling Technology, Inc.); and rabbit anti-serine/threonine protein kinase mTOR (mTOR; cat no. 2972) and p-mTOR (cat no. 5536; 1:1,000; Cell Signaling Technology, Inc.). Following washing in TBS with Tween-20, the membranes were incubated at $37^{\circ} \mathrm{C}$ for $2 \mathrm{~h}$ with horseradish peroxidase-conjugated secondary antibodies (cat no. ZB-2301; 1:1,000; ZSGB-Bio, Beijing, China). Following further washing, the immunoreactive bands were visualized using an enhanced chemiluminescence reagent (cat no. WBKLS0500; EMD Millipore, Billerica, MA, USA). The optical density of each blot was measured, and the relative expression of target proteins was calculated and normalized to the housekeeping protein actin, using Quantity One software version 4.5.2 (Bio-Rad Laboratories, Inc.).

Immunofluorescence. MDA-MB-231 and MCF-7 breast cancer cells $\left(2 \times 10^{5}\right.$ cells) were grown on slides $(8 \times 8 \mathrm{~mm})$ in 24 -well plates. When the cells had reached $60 \%$ confluence, they were treated with IL-12 $(5 \mathrm{ng} / \mathrm{ml})$ for $24 \mathrm{~h}$, followed by washing 3 times in pre-cooled PBS. The cells were fixed in $4 \%$ paraformaldehyde for $20 \mathrm{~min}$ at room temperature, penetrated with $0.1 \%$ Triton X-100 (diluted in PBS) for 15 min and blocked with $10 \%$ goat serum (Sangon Biotech Co., Ltd., Shanghai, China) for $30 \mathrm{~min}$ at room temperature. The cells were incubated overnight at $4^{\circ} \mathrm{C}$ with rabbit anti-LC3 primary antibody $(1: 200$ diluted in $10 \%$ goat serum). Following rinsing, the cells were incubated with fluorescein isothiocyanate (FITC)-conjugated secondary antibody (cat no. ZF-0314; 1:200 dilution in 10\% goat serum; ZSGB-Bio) away from light at room temperature for $2 \mathrm{~h}$. Following further washing, the cells were stained with $10 \%$ DAPI (diluted in PBS) for $5 \mathrm{~min}$ at room temperature, washed 3 times and sealed with $70 \%$ glycerol, prior to visualization using a fluorescence microscope (Nikon Corporation, Tokyo, Japan). Images were captured of DAPI and FITC in the same field of view.

Transmission electron microscopy (TEM). MDA-MB-231 and MCF-7 cells were grown on culture dishes and treated with rIL-12 (5 ng/ml) for $12 \mathrm{~h}$, prior to washing 3 times in cold PBS $\left(4^{\circ} \mathrm{C}\right)$. The cells were digested with $0.1 \%$ trypsin and collected by centrifugation at $1,500 \mathrm{xg}$ and $4^{\circ} \mathrm{C}$ for $10 \mathrm{~min}$. The supernatant was removed. Glutaraldehyde fixative $(2.5 \%, 1.5 \mathrm{ml})$ was added along the side of a disposable micro-centrifuge tube for treatment at $4^{\circ} \mathrm{C}$ for $>2 \mathrm{~h}$. Following rinsing, dehydration, saturation and embedding with epoxy resin at $35^{\circ} \mathrm{C}$ for $>12 \mathrm{~h}$, the cell samples $(60 \mathrm{~nm})$ were examined using a Hitachi-7500 transmission electron microscope (Hitachi, Ltd., Tokyo, Japan).

Statistical analysis. Each experiment was performed $\geq 3$ times. Experimental data were analyzed using one-way analysis of variance and least significant difference tests. SPSS software (version 19.0; IBM Corp., Armonk, NY, USA) was used to perform the statistical analyses. $\mathrm{P}<0.05$ was considered to indicate a statistically significant difference.

\section{Results}

IL-12 enhances the expression of LC3 protein in human breast cancer cells. In order to assess the effects of rIL-12 on human breast cancer cell autophagy, MDA-MB-231 and MCF-7 breast cancer cells were treated with $5 \mathrm{ng} / \mathrm{ml} \mathrm{rIL-12}$ for $1,2,3,6,12$ or $24 \mathrm{~h}$, or with $0.1,0.5,1,5,10$ or $20 \mathrm{ng} / \mathrm{ml}$ rIL-12 for $12 \mathrm{~h}$, to determine the time- and dose-effect associations. In addition, the expression of LC3 induced by $5 \mathrm{ng} / \mathrm{ml} \mathrm{rIL}-12$ was detected using immunofluorescence. MDA-MB-231 and MCF-7 breast cancer cells were treated by serum starvation for $3 \mathrm{~h}$ to act as positive controls. Western 
A B Ih $2 \mathrm{~h} \quad 3 \mathrm{~h} \quad 6 \mathrm{~h} \quad 12 \mathrm{~h} \quad 24 \mathrm{~h} \quad \mathrm{P}$ 231

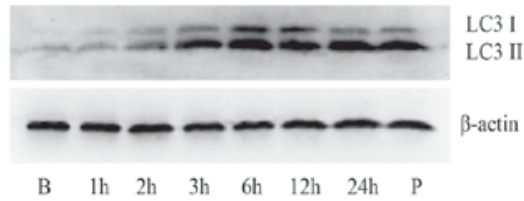

B Ih $2 \mathrm{~h} \quad 3 \mathrm{~h} \quad 6 \mathrm{~h} \quad 12 \mathrm{~h} \quad 24 \mathrm{~h} \quad \mathrm{P}$

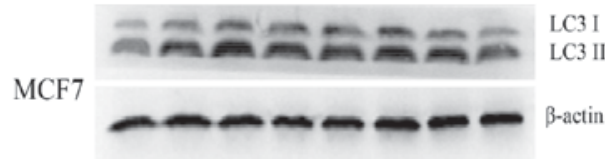

$\mathrm{B}$ B $\quad 0.1 \quad 0.5 \quad 1 \quad 5 \quad 10 \quad 20(\mathrm{ng} / \mathrm{ml})$

231

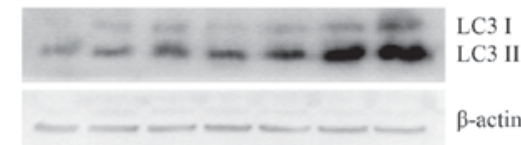

$\begin{array}{lllllll}\text { B } & 0.1 & 0.5 & 1 & 5 & 10 & 20(\mathrm{ng} / \mathrm{ml})\end{array}$

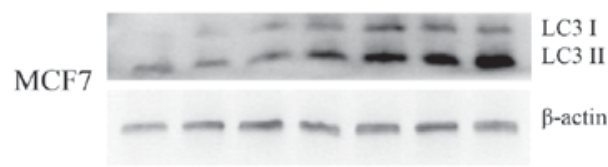

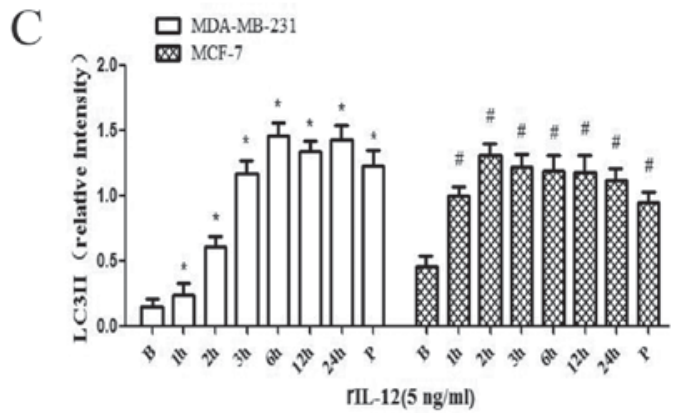

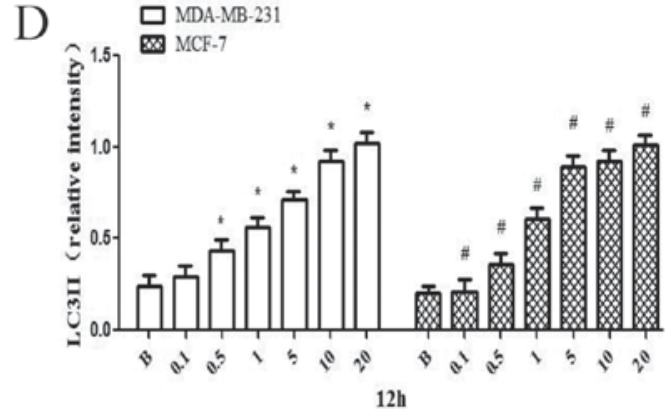

Figure 1. Western blot analysis of LC3 expression in breast cancer cells induced by IL-12. (A) The breast cancer cells were treated with rIL-12 (5 ng/ml) for 1, 2, 3, 6, 12 and $24 \mathrm{~h}$. The cells in the P group were starved for $3 \mathrm{~h}$. The whole-cell lysates were analyzed using western blotting. The results demonstrated that IL-12 increased the expression of LC3 in a time-dependent manner, particularly the expression of LC3II. (B) The breast cancer cells were treated with $0.1,0.5,1,5,10$ and $20 \mathrm{ng} / \mathrm{ml}$ rIL-12 for $12 \mathrm{~h}$. The whole-cell lysates were analyzed using western blotting. The results demonstrated that IL-12 upregulated the expression of LC3II in a dose-dependent manner. (C) Quantification of the results of the western blotting from cells treated for varying lengths of time. (D) Quantification of the results of the western blotting from cells treated with varying concentrations. ${ }^{*} \mathrm{P}<0.05$ vs. MDA-MB-231 B group. ${ }^{\#} \mathrm{P}<0.05$ vs. MCF-7 B group. B, negative control; P, positive control; rIL-12, recombinant interleukin-12; LC3, microtubule-associated protein light chain 3.

blot analysis revealed that the expression of the autophagy marker protein LC3 in breast cancer cells was enhanced by treatment with IL-12, particularly the expression of LC3II. It was observed that IL-12 induced the expression of LC3II in a concentration- and time-dependent manner (Fig. 1). Consistently, the immunofluorescence results indicated that IL-12 upregulated the protein expression of LC3. LC3 protein stained with FITC was observed to be aggregated around the cell nucleus, and the stimulation effect of $5 \mathrm{ng} / \mathrm{ml} \mathrm{rIL-12} \mathrm{on}$ LC3II protein expression increased compared with the positive control (Fig. 2).

IL-12 induces the formation of autophagosomes. TEM is the gold-standard method of analyzing autophagosome formation. MDA-MB-231 and MCF-7 breast cancer cells were treated with $5 \mathrm{ng} / \mathrm{ml} \mathrm{rIL}-12$ for $12 \mathrm{~h}$. Following digestion with trypsin and preparation of the samples, cells were observed using TEM to view the micro-morphological characteristics of the autophagosome. The autophagosome is a foam-like structure with a double or multilayer membrane. In the later stages of autophagy, autophagosomes appear to be vesicular with inclusions. In the present study, autophagosomes were observed in the IL-12 group (Fig. 3). The results of the present study indicated that IL-12 is able to induce autophagosome formation in breast cancer cells.

IL-12 induces the expression of LC3 protein in breast cancer cells by inhibiting the Akt pathway and activating the AMPK pathway. In order to study alterations in the expression of
LC3 proteins induced by IL-12, the cells were divided into a number of groups. In the IL-12+IGF-1/BML-275 groups, MDA-MB-231 and MCF-7 breast cancer cells were pretreated with $100 \mathrm{ng} / \mathrm{ml} \mathrm{IGF-1,} \mathrm{a} \mathrm{PI3K/Akt} \mathrm{activator,} \mathrm{or} 10 \mu \mathrm{mol} / \mathrm{ml}$ BML-275, an AMPK inhibitor, for $2 \mathrm{~h}$. A total of $5 \mathrm{ng} / \mathrm{ml}$ rIL-12 was added for a further $4 \mathrm{~h}$. The IL-12 groups were treated with $5 \mathrm{ng} / \mathrm{ml}$ rIL-12 only for $4 \mathrm{~h}$.

It was observed that the expression of p-PI3K/Akt was inhibited by IL-12, and p-mTOR was additionally downregulated. LC3 protein expression, particularly LC3II, was upregulated in the IL-12 group compared with the negative control group. The expression levels of p-PI3K/Akt and p-mTOR recovered when the cells were treated with IGF-1 to activate the PI3K/Akt pathway, and the expression of LC3II protein was inhibited (Fig. 4A). In addition, it was observed that the expression of p-AMPK was activated by IL-12 and p-mTOR was simultaneously downregulated. As the p-AMPK pathway was inhibited by BML-275, the ability of IL-12 to induce the expression of LC3II in the BML-275-treated cells was decreased (Fig. 4B).

Consistent results were observed in the immunofluorescence assay. The fluorescence intensities of LC3 proteins were increased by IL-12. However, this effect was reversed when the cells were pretreated with IGF-1 or BML-275 (Fig. 4C and D). The results of the present study demonstrated that IL-12 upregulated the expression of LC3 proteins and promoted the autophagy of MDA-MB-231 and MCF-7 breast cancer cells, due to inhibition of the PI3K/Akt signaling pathway and activation of the AMPK signaling pathway. 


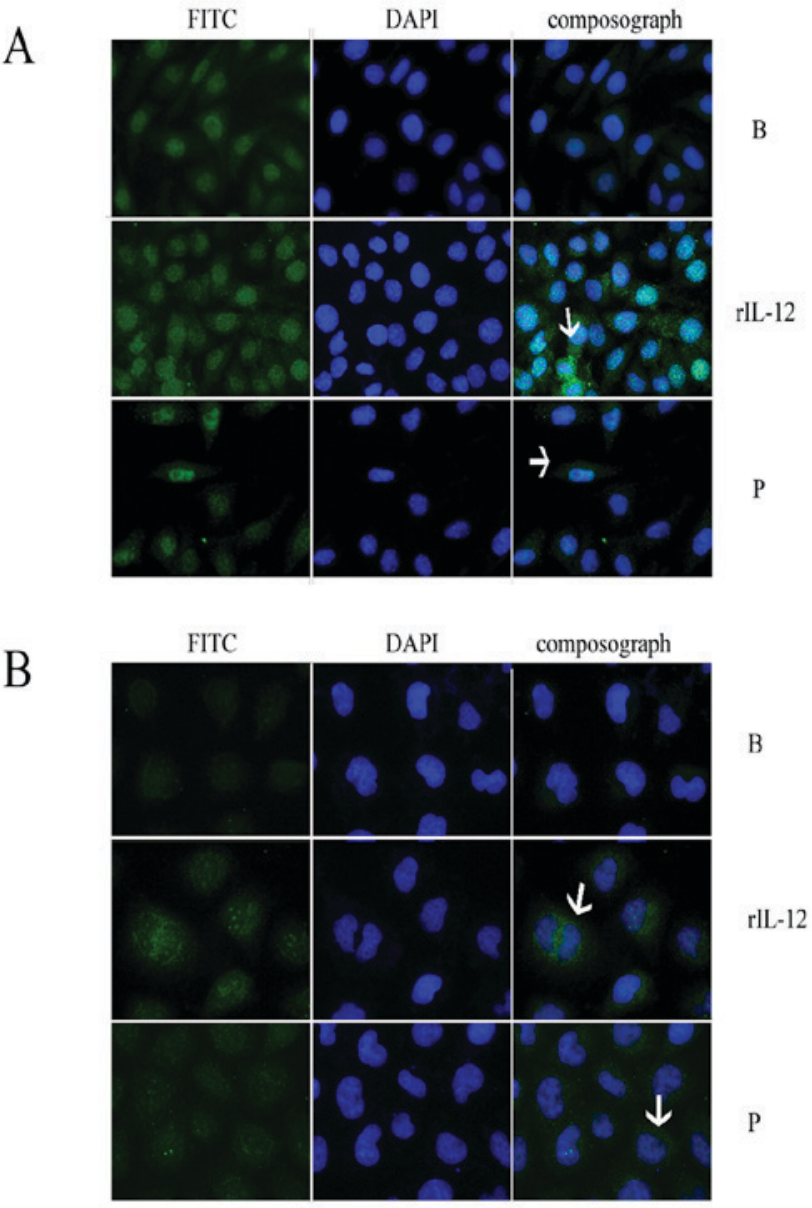

Figure 2. Immunofluorescence analysis of LC3 expression in breast cancer cells treated with IL-12. Untreated breast cancer cells acted as the B group. The cells in group $\mathrm{P}$ were starved for $3 \mathrm{~h}$. The breast cancer cells were treated with $5 \mathrm{ng} / \mathrm{ml} \mathrm{rIL}-12$ for 6,12 and $24 \mathrm{~h}$. The cells were observed using a fluorescence microscope. The results indicated that IL-12 upregulated the expression of LC3. White arrows indicate aggregation around the cell nucleus. The results at $12 \mathrm{~h}$ are presented. (A) MDA-MB-231 cells. (B) MCF-7 cells. B, negative control; $\mathrm{P}$, positive control; rIL-12, recombinant interleukin-12; LC3, microtubule-associated protein light chain; FITC, fluorescein isothiocyanate.

\section{Discussion}

Autophagy is a Greek term coined by Christian DeDuve to mean 'self-digesting' (17). The process of autophagy may be divided into three parts. The first phase begins with the activation of mTOR. mTOR is an atypical serine/threonine protein kinase and is associated with cell growth. The second phase is the regulation of autophagy related gene (Atg), which is regulated by interactions between proteins or signal transduction molecules. The third phase is the late stage of autophagy regulation, and is associated with autophagosome maturation and lysosome-phagosome fusion (18). Autophagy was first associated with human cancer due to the identification of beclin 1, an autophagy associated gene, as a haploid-insufficient tumor suppressor. Beclin 1 has been mapped to a tumor susceptibility locus on human chromosome 17q21, which is monoallelically deleted in $40-75 \%$ of ovarian, breast and prostate cancer, suggesting that it may act as a tumor suppressor $(8,19)$.

At present, autophagy research was primarily based on the direct observation of autophagosomes, or the indirect detection

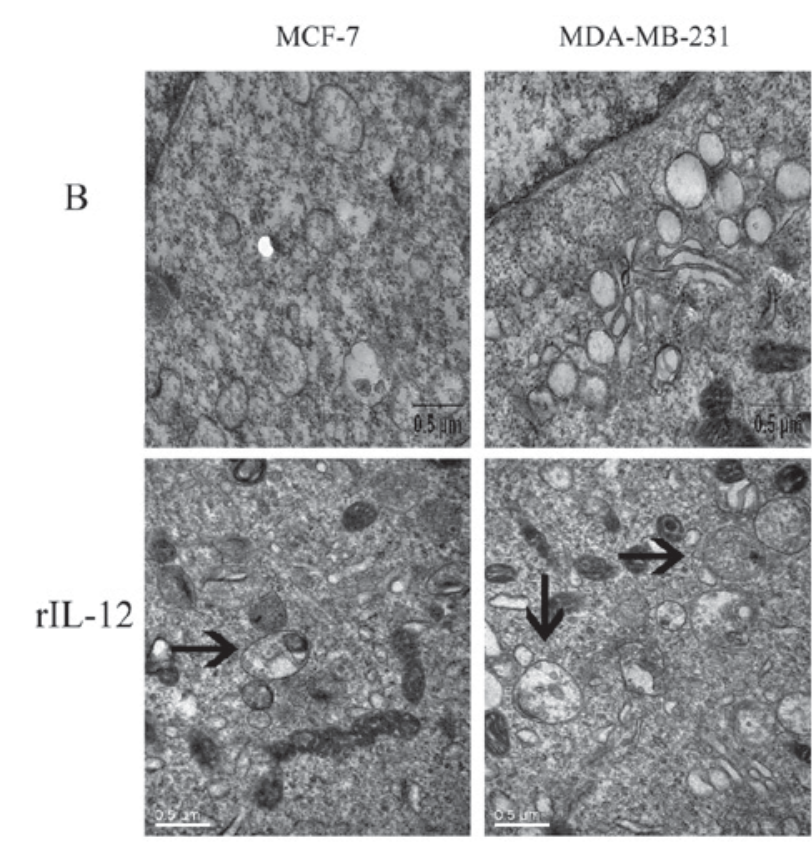

Figure 3. Transmission electron microscopy analysis of autophagosomes in breast cancer cells treated with IL-12. The untreated breast cancer cells acted as the B group. The rIL-12 groups of breast cancer cells were treated with $5 \mathrm{ng} / \mathrm{ml} \mathrm{rIL-12}$ for 12 . The results demonstrated that IL-12 promoted autophagosome formation. The black arrows indicate the autophagosomes, which exhibit double membranes or inclusions. Magnification, x30,000. B, negative control; IL-12, recombinant interleukin-12.

of surface markers or associated proteins. Comprehensive evaluation of the function of autophagy and the control of autophagic pathways in cell behavior is required. Electron microscopy remains one of the most accurate methods for the detection of autophagy and the quantification of autophagosome accumulation. Autophagosomes exhibit a foam-like structure with a double or multilayer membrane, and contain numerous types of undigested organelles. Following fusion with lysosomes, autophagosomes assume the form of a monolayer with undigested organelles (20). An alternative method of studying autophagy is based on LC3 protein expression. During the production of autophagosomes, cytoplasmic LC3I proteins are converted to LC3II proteins in the membrane of autophagosome. Alterations in autophagy may be investigated indirectly by assessing LC3 protein expression $(21,22)$. In the present study, it was demonstrated that IL-12 is able to upregulate cellular autophagy in MDA-MB-231 and MCF-7 breast cancer cells, using TEM and LC3 protein expression analysis. The alteration in LC3 protein expression was detected using western blotting and immunofluorescence.

In the first phase of autophagy regulation, the PI3K/Akt-mTOR and AMPK-mTOR signaling pathways serve important roles. The activation of autophagy is associated with the inhibition of PI3K/Akt-mTOR and mTOR, or the activation of AMPK (4). In previous studies, Zhang et al $(23,24)$ and Danielsen et al (25) demonstrated that activation of Akt pathway was associated with the inhibition of cellular apoptosis and the promotion of cell proliferation. Guo et al (26) observed that transforming growth factor $\beta 1$ (TGF $\beta 1$ ) was overexpressed in various types of cancer. TGF $\beta 1$ overexpression in cancer cells may activate the Akt pathway and 
A

MCF-7

B IL-12 IL-12+IGF-1

B IL-12 IL-12+IGF-I
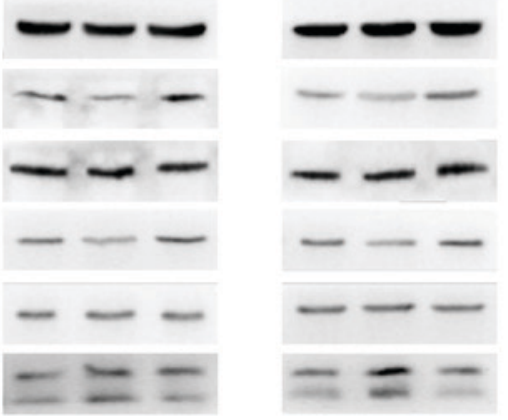

$\beta$-actin

p-AKT

AKT

p-mTOR

mTOR

LC3 I

LC3 II

B

MDA-MB-231

MCF-7

B $\quad$ IL-12 IL-12+BML-275

B $\quad$ LL-12 IL-12+BML-275

C

B

rIL-12
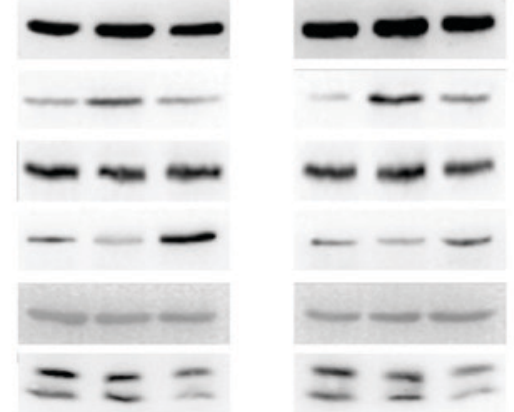

$\beta$-actin

p-AMPK

AMPK

p-mTOR

mTOR

LC3 I

LC3 II
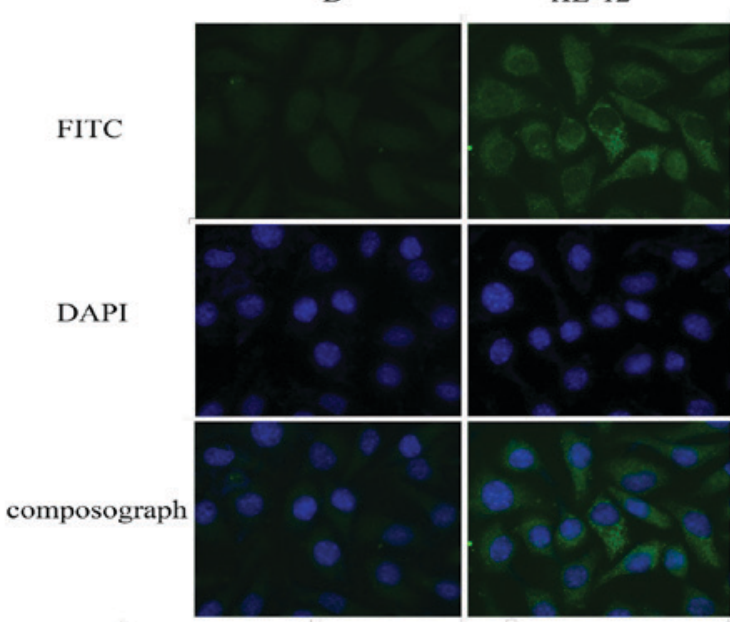

rIL-12+IGF-1

rIL-12+BML-275
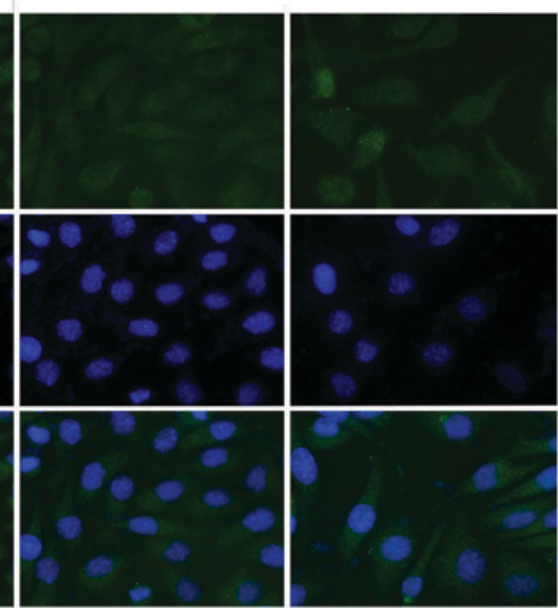

D

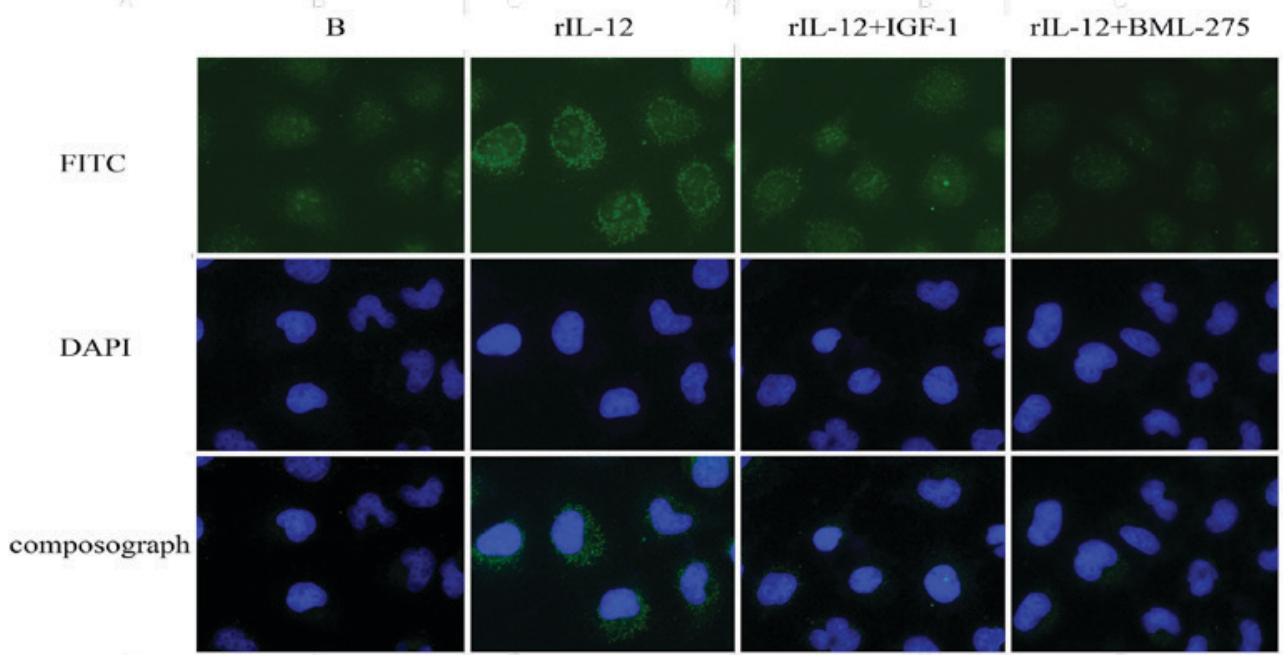

Figure 4. IL-12 induced the expression of LC3 in breast cancer cells by inhibiting the PI3K/Akt pathway and activating AMPK pathway. The breast cancer cell groups IL-12+IGF-1 and IL-12+BML-275 were pretreated with $100 \mathrm{ng} / \mathrm{ml} \mathrm{IGF-1} \mathrm{or} 10 \mu \mathrm{mol} / \mathrm{ml} \mathrm{BML-275}$, respectively, for $2 \mathrm{~h}$. A total of $5 \mathrm{ng} / \mathrm{ml} \mathrm{rIL}-12$ was added for a further $4 \mathrm{~h}$. The IL-12 groups were treated with $5 \mathrm{ng} / \mathrm{ml} \mathrm{rIL}-12$ for $4 \mathrm{~h}$. $\beta$-actin, p-Akt/Akt, p-mTOR/mTOR, pAMPK/AMPK and LC3 proteins were detected using western blotting: (A) IL-12+IGF-1 groups and (B) IL-12+BML-275 groups. The expression and distribution of LC3 proteins was examined using fluorescence microscopy with FITC-labeled secondary antibodies in (C) MDA-MB-231 and (D) MCF-7. B, negative control; rIL-12, recombinant interleukin-12; LC3, microtubule-associated protein light chain; FITC, fluorescein isothiocyanate; PI3K, phosphatidylinositol 3-kinase; Akt, Rac- $\alpha$ serine/threonine protein kinase; AMPK, 5'-AMP-activated protein kinase subunit $\beta$-1; IGF-1, insulin-like growth factor 1; mTOR, serine/threonine protein kinase mTOR.

enhance cell proliferation and migration. The Akt signaling pathway is able to activate numerous downstream targets, including mTOR complex 1, which inhibits tumor formation. Previous studies have demonstrated that the inactivation of negative regulatory proteins upstream of mTOR occurs in tumors $(27,28)$. The inactivation of the phosphatase and tensin homolog gene (PTEN) is frequently observed in breast cancer, thyroid carcinoma and prostate cancer. The inactivation of PTEN is associated with the oncogenic activity of Akt and the activity of the mTOR signaling pathway. It is due to these 
associations that rapamycin may be used to treat cancer (29). AMPK is a sensor of cellular energetic status expressed in all eukaryotes. Previous studies have indicated that AMPK activation inhibits cell proliferation in tumor cells, which require increased rates of protein synthesis and de novo fatty acid synthesis due to their rapid growth. The AMPK signaling pathway is associated with tumor growth and proliferation through regulation of the mTOR pathway. Therefore, AMPK is emerging as an important metabolic tumor suppressor and a promising target for cancer prevention and therapy $(30,31)$.

In order to elucidate the mechanism of IL-12-induced autophagy in breast cancer cells, the involvement of the PI3K/Akt and AMPK signaling pathways was investigated. It was observed that the induction of autophagy-associated protein expression by IL-12 accompanied the decrease in p-AKT and increase in p-AMPK in breast cancer cells. However, following activation of the PI3K/Akt pathway by IGF-1, the ability of IL-12 to promote the expression of LC3 was inhibited, and the expression of mTOR was recovered in the IL-12 group. The AMPK pathway was inhibited by BML-275, and it was observed that the alteration of LC3 and mTOR expression was consistent compared with cells treated with the PI3K/Akt activator IGF-1. The results of the present study demonstrated that IL-12 is able to induce autophagy by inhibiting the PI3K/Akt signaling pathway and activating the AMPK signaling pathway.

In conclusion, the results of the present study demonstrated that IL-12 was able to induce autophagy in breast cancer cells in a time- and concentration-dependent manner, by inhibiting PI3K/Akt and activating the AMPK signaling pathway. The present study may offer a novel insight into the IL-12 anticancer mechanism.

\section{References}

1. Gezagen GG, Roach EC, Kizilarslanoglu MC, Petekkaya I and Altundag K: Metabolic syndrome and breast cancer: An overview. J BUON 17: 223-229, 2012.

2. Jemal A, Bray F, Center MM, Ferlay J, Ward E and Forman D: Global cancer statistics. CA Cancer J Clin 61: 69-90, 2011.

3. Mizushima N, Levine B, Cuervo AM and Klionsky DJ: Autophagy fights disease through cellular self-digestion. Nature 451: 1069-1075, 2008

4. Chen N and Karantza V: Autophagy as a therapeutic target in cancer. Cancer Biol Ther 11: 157-168, 2011.

5. White E and DiPaola RS: The double-edged sword of autophagy modulation in cancer. Clin Cancer Res 15: 5308-5316, 2009.

6. Komatsu M, Waguri S, Koike M, Sou YS, Ueno T, Hara T, Mizushima N, Iwata J, Ezaki J, Murata S, et al: Homeostatic levels of p62 control cytoplasmic inclusion body formation in autophagy-deficient mice. Cell 131: 1149-1163, 2007.

7. Palumbo S, Pirtoli L, Tini P, Cevenini G, Calderaro F, Toscano M, Miracco C and Comincini S: Different involvement of autophagy in human malignant glioma cell lines undergoing irradiation and temozolomide combined treatments. J Cell Biochem 113 2308-2318, 2012

8. Liang XH, Jackson S, Seaman M, Brown K, Kempkes B, Hibshoosh $\mathrm{H}$ and Levine B: Induction of autophagy and inhibition of tumorigenesis by beclin 1. Nature 402: 672-676, 1999.

9. Qu X, Yu J, Bhagat G, Furuya N, Hibshoosh H, Troxel A, Rosen J, Eskelinen EL, Mizushima N, Ohsumi Y, et al: Promotion of tumorigenesis by heterozygous disruption of the beclin 1 autophagy gene. J Clin Invest 112: 1809-1820, 2003.
10. Yue Z, Jin S, Yang C, Levine AJ and Heintz N: Beclin 1, an autophagy gene essential for early embryonic development, is a haploinsufficient tumor suppressor. Proc Natl Acad Sci USA 100: 15077-15082, 2003.

11. Kondo Y and Kondo S: Autophagy and cancer therapy. Autophagy 2: 85-90, 2006.

12. Xu M, Mizoguchi I, Morishima N, Chiba Y, Mizuguchi J and Yoshimoto T: Regulation of antitumor immune responses by the IL-12 family cytokines, IL-12, IL-23, and IL-27. Clin Dev Immunol 2010: pii: 832454, 2010.

13. Sangro B, Melero I, Qian C and Prieto J: Gene therapy of cancer based on interleukin 12. Curr Gene Ther 5: 573-581, 2005.

14. Suzuki K, Nakaji S, Kurakake S, Totsuka M, Sato K, Kuriyama T, Fujimoto H, Shibusawa K, Machida K and Sugawara K: Exhaustive exercise and type-1/type-2 cytokine balance with special focus on interleukin-12 p40/p70. Exerc Immunol Rev 9: 48-57, 2003.

15. Sgadari C, Angiolillo AL and Tosato G: Inhibition of angiogenesis by interleukin-12 is mediated by the interferon-inducible protein 10. Blood 87: 3877-3882, 1996.

16. Ma TT, Wu BT, Lin Y, Xiong HY, Wang Q, Li ZW, Cheng F and Tu ZG: IL-12 could induce monocytic tumor cells directional differentiation. Mol Cell Biochem 402: 157-169, 2015.

17. Chen Y, Azad MB and Gibson SB: Methods for detecting autophagy and determining autophagy-induced cell death. Can J Physiol Pharmacol 88: 285-295, 2010.

18. Liu Y and Levine B: Autosis and autophagic cell death: The dark side of autophagy. Cell Death Differ 22: 367-376, 2015.

19. Zhi X and Zhong Q: Autophagy in cancer. F1000Prime Rep 7: $18,2015$.

20. Ylä-Anttila P, Vihinen H, Jokitalo E and Eskelinen EL: Monitoring autophagy by electron microscopy in Mammalian cells. Methods Enzymol 452: 143-164, 2009.

21. Mizushima N and Yoshimori T: How to interpret LC3 immunoblotting. Autophagy 3: 542-545, 2007.

22. Kimura S, Fujita N, Noda T and Yoshimori T: Monitoring autophagy in mammalian cultured cells through the dynamics of LC3. Methods Enzymol 452: 1-12, 2009.

23. Zhang J, Zhao D, Xie Z and Qi Y: Down-regulation of AKT combined with radiation-induced autophagy and apoptosis roles in MCF-7 cells. Biomed Mater Eng 26 (Suppl 1): S2259-S2265, 2015.

24. Zhang J, Yu XH, Yan YG, Wang C and Wang WJ: PI3K/Akt signaling in osteosarcoma. Clin Chim Acta 444: 182-192, 2015.

25. Danielsen SA, Eide PW, Nesbakken A, Guren T, Leithe E and Lothe RA: Portrait of the PI3K/AKT pathway in colorectal cancer. Biochim Biophys Acta 1855: 104-121, 2015.

26. Guo YS, Zhao R, Ma J, Cui W, Sun Z, Gao B, He S, Han YH, Fan J, Yang L, et al: $\beta$ ig-h3 promotes human osteosarcoma cells metastasis by interacting with integrin $\alpha 2 \beta 1$ and activating PI3K signaling pathway. PLoS One 9: e90220, 2014.

27. Vigneswaran N, Wu J, Song A, Annapragada A and Zacharias W: Hypoxia-induced autophagic response is associated with aggressive phenotype and elevated incidence of metastasis in orthotopic immunocompetent murine models of head and neck squamous cell carcinomas (HNSCC). Exp Mol Pathol 90: 215-225, 2011.

28. Levine B and Klionsky DJ: Development by self-digestion: Molecular mechanisms and biological functions of autophagy. Dev Cell 6: 463-477, 2004.

29. Zheng HY, Zhang XY, Wang XF and Sun BC: Autophagy enhances the aggressiveness of human colorectal cancer cells and their ability to adapt to apoptotic stimulus. Cancer Biol Med 9: 105-110, 2012

30. Motoshima H, Goldstein BJ, Igata M and Araki E: AMPK and cell proliferation-AMPK as a therapeutic target for atherosclerosis and cancer. J Physiol 574: 63-71, 2006.

31. Luo Z, Saha AK, Xiang X and Ruderman NB: AMPK, the metabolic syndrome and cancer. Trends Pharmacol Sci 26: 69-76, 2005. 